\title{
Sustentabilidade econômica da atividade pesqueira em Santa Catarina*
}

\author{
Julio Cesar Lopes Borges ${ }^{1}$ \\ Universidade Federal de Santa Catarina
}

Ao se estabelecerem no litoral catarinense, açorianos e madeirenses, por volta de 1740-60, exerceram as atividades permitidas pela Coroa portuguesa. Entre elas estavam à pesca da baleia, que a princípio demonstrou grande importância para os primeiros povoados. Porém, quando esta atividade se mostrou incapaz de produzir à vida material nos povoados a pequena agricultura virou atividade permanente, aliada também à pesca de subsistência ou o que chamamos hoje de pesca artesanal. Este estudo busca demonstrar de forma descritiva estas mudanças nas atividades exercidas no litoral de Santa Catarina até a constituição do que hoje chamamos de setor pesqueiro. E que no decorrer destas relações estabelecidas entre estado, indústria - capitalista e o trabalho, na busca pela industrialização de tal atividade acaba por gerar conflitos de uso de um bem comum, o mar. Ao final verificaremos o teor da crise instalada no litoral, resultado das relações estabelecidas entre o homem e a natureza quando reina a lógica do mercado.

Palavras-chave: Industrialização - Pesca artesanal - Políticas pesqueiras nacionais.
When immigrants from Island of Açores and Island of Madeira arrived in Santa Catarina coastline, around year of 1740-1760, they practiced the activities permitted by the Portuguese Monarchy. Fishing for the whale was one of those activities, which initially showed great importance for the village. However, when whaling was unable to produce the material life in the villages, the small agriculture activity became permanent, along with the fish for subsistence or what we call today the fishing craft. The present study demonstrates the changes in the practical activity at coastline of Santa Catarina till the establishment of the fisheries sector. This paper also shows that in the course of the relations between the state, capitalist industry and the work - in search for industrialization of this activity - generated conflict in the sea use. In addition, we demonstrate that the crisis installed in the coastline - result of the established relations between the men and nature where the market logic prevailed.

Keywords: Industrialization - Fishing craft - National polices fishing.

\section{Introdução}

Sem dúvida a atividade pesqueira em Santa Catarina obteve um grande $\checkmark$ desempenho na captura a partir da década de 1950. As políticas do governo federal para com a pesca, desde o período colonial, começaram a surtir

\footnotetext{
* Economic value of the fishery activity in Santa Catarina state

${ }^{1}$ Endereço para correspondências: Universidade Federal de Santa Catarina, Centro Sócio-Econômico, Curso de Economia EAD, Trindade, Florianópolis, SC, 88040-970 (juliocborges@yahoo.com.br).
} 
efeito durante o governo do presidente Juscelino Kubitschek, onde foi encaminhado ao congresso nacional os Planos de Desenvolvimento Pesqueiro (PNDP) e paralelo a isso, os ensaios na tentativa de criar uma indústria capitalista de pesca no país, sobretudo em Santa Catarina, onde apresentava um dos maiores litorais brasileiros para execução de tal atividade econômica. Ainda, o litoral catarinense apresentava uma estrutura pesqueira baseada em embarcações artesanais e pescadores organizados na forma de campanhas, estes pescadores eram singulares e ainda o são, pois possuíam um conhecimento secular da atividade pesqueira, além de possuir adequado aparato de pesca.

A atividade pesqueira no Brasil assim como em Santa Catarina, era predominantemente artesanal em meados da primeira metade do século XX, e sua produção estava voltada basicamente para atender o mercado interno. A partir de então, através de uma política de incentivos fiscais à pesca, desenvolve-se a chamada pesca industrial, voltada, preferencialmente, para o mercado externo. Um dos exemplos mais importantes é o da Companhia Krauser, uma das maiores do Brasil. A Krauser possuía já nestas décadas um enorme setor de captura, beneficiamento, e comercialização. Segundo os relatórios da SUDEPE, contidos nos dois primeiros Planos Nacionais de Desenvolvimento Pesqueiro (PNDP) foi à indústria capitalista de pesca que mais recebeu incentivos estatais no Brasil.

Além da Krauser, também a Sopesca, a Tripalli, a Ensol, a Navepesca, a Kowalski, Itasul, a José Vasques Martinez, a David Gregório Neto, a Sul Atlântico, a Qualker, a Serpa, a Mipesca, a Tripalli e Delmar, entre outras, foram beneficiadas por políticas estatais de grande envergadura. Tais incentivos introduziram as traineiras, a proletarização do trabalho flutuante e novas tecnologias de captura. O crescimento do parque industrial pesqueiro Catarinense, nos anos de 1960/70, que foi, em grande parte, impulsionado pelas políticas de promoção ao desenvolvimento da atividade pesqueira, que ocasionou no crescimento do volume de produção pesqueira, mas sem a preocupação com a conservação do estoque natural do pescado, levou à diminuição do número de indústrias pesqueiras ao final da década de 1980, pois já não havia pescado suficiente para suprir as necessidades de toda a indústria.

É importante ressaltar que a pesca artesanal não foi historicamente beneficiada com recursos financeiros das políticas públicas, que juntamente com a diminuição dos recursos pesqueiros houve descapitalização do segmento pesqueiro artesanal, apesar da atividade pesqueira envolver grande número de pescadores e por contar com o estoque natural do pescado como fonte básica de ganhos, ou seja, a pesca artesanal até 1950 representava mais de $50 \%$ da exploração, com uma íntima relação entre homem e natureza. Ainda, o pescador artesanal foi prejudicado pela exploração irracional do pescado, 
acarretando impactos negativos para a sobrevivência da comunidade dos pescadores artesanais, dado que as transformações ocorridas no ambiente aquático refletem-se nestas comunidades, a saber, nos povoados mais tradicionais açorianos em Santa Catarina.

Enquanto a pesca industrial se beneficiava dos polpudos incentivos, a pesca artesanal, nos relatórios da SUDEPE (Superintendência do Desenvolvimento da Pesca), passava por uma crise sócio-ambiental. Estes fatores, descapitalização dos pescadores artesanais, quebra das indústrias, diminuição do estoque natural de peixes (diminuição da produção), caracterizam a crise que se instalou na atividade pesqueira Catarinense, sobretudo, a partir da década de 1980.

\section{Fundamentação teórica}

De acordo com Marx (1963), inicialmente, ao analisar a produção da vida material humana, é importante considerar uma diferença entre objeto de trabalho e meio de trabalho (matéria prima). O objeto de trabalho é aquele objeto natural retirado da natureza pelo trabalho e transformado em valor de uso, mais ainda, em meio de subsistência. Já, quando um objeto de trabalho tem o trabalho incorporado, é chamado por ele de meio de trabalho ou matéria prima. Ou dito de outra forma, as condições naturais externas de produção dividem-se sob o ponto de vista econômico, em duas grandes categorias: riquezas naturais como meio de subsistência, como: águas piscosas, e riquezas naturais como meio de trabalho, tais como os rios navegáveis, madeira, em fim. No primeiro caso, os recursos naturais são simplesmente objeto de trabalho, onde se aplica os instrumentos de produção, ou onde o homem retira o fruto, seja pela pesca ou outras formas.

Ao considerar a água em seu estado virgem como grande fornecedor dos meios de subsistência para o homem, Karl Marx vê nela um objeto de trabalho humano. Tudo aquilo que o homem simplesmente separa do ambiente natural são objetos de trabalho, fornecidos espontaneamente pela natureza. Poderíamos dizer então que o mar e seus recursos se transformam em instrumentos de produção quando se aproveitam suas correntes para produção de energia, ou ainda, quando, aproveitam as forças naturais, quando o homem passa a cultivar o peixe através da aqüicultura.

No caso da pesca, devido aos processos naturais (maior fertilidade das águas), pode ocorrer que o pescador retire das águas um volume considerável de pescado sem grande esforço. Pode-se afirmar então que, nessas condições favoráveis, o tempo de trabalho necessário a produção dos meios de subsistência é menor do que em outras situações. Ainda, a pesca enquanto meio de subsistência indica um estágio da produção em que o homem e seu trabalho se confundem com as condições naturais de produção. 


\section{HUMANAS}

A indústria de pesca, ainda que dependa menor das forças da natureza para produzir, nem assim está livre dos limites que impõe os próprios recursos naturais. Com um arrastão-fábrica devastador, pode-se até certo ponto, superar os condicionamentos físicos humanos a que está sujeito o pescador artesanal e sua embarcação. Estes limites são dados, ainda, pela capacidade limitada de reprodução dos peixes no mar, residindo um ponto importante na compreensão da atividade pesqueira, esquecido muitas vezes por aqueles que analisam a pesca como idêntica aos outros setores da divisão social da produção e do trabalho.

Conforme (DIEGUES, 1978), a pesca em si não é somente uma atividade econômica, mas também é onde homens cultivam saberes e culturas distintas, onde além das relações capitalistas de produção existam cultura e relações diversas, um cotidiano peculiar. Porém não há como negar que na pesca a exploração da força de trabalho se fez concomitantemente à destruição gradativa das forças da natureza. O desaparecimento de inúmeras espécies de pescado se deu não somente pela sobrepesca ${ }^{2}$, facilitada pela introdução do maquinismo e técnicas cada vez mais predatórias, como também dos efeitos negativos da poluição proveniente dos dejetos urbano-industriais.

A diversa espécie existente num determinado ecossistema se relaciona dentro da cadeia trófica, pelas quais espécies servem de alimentos umas as outras. $\mathrm{O}$ desconhecimento ou o desrespeito a esse processo complexo tem levado, especialmente através da captura indiscriminada em larga escala, no século XX, em Santa Catarina, a verdadeiros desastres ecológicos pelos quais espécies inteiras de pescado desapareceram e não puderam se reproduzir. Muitas vezes, estrutura de demanda centrada sobre animais marinhos que estavam na base de importantes cadeias tróficas levaram a sobrepesca dessas espécies que por sua vez comprometeram a existência de peixes que dela se nutrem. Por isso é preciso ser levado em conta às inúmeras características dos processos de produção na pesca.

\section{A pesca de subsistência}

No início do Século XVIII, em Santa Catarina, a pesca era feita geralmente por pequenos agricultores da região coagidos mesmo à força, pois a atividade era perigosa e o seu trabalho era pago de acordo com o número de baleias pescadas. A pesca da baleia era a atividade mais rentável no litoral sul, o óleo extraido era utilizado para iluminação e produção de liga para argamassa, e, após a segunda metade do século XVIII também a cera para velas. Para a confecção do óleo, a gordura era tirada da baleia e derretida em tanques no engenho de frigir.

${ }^{2}$ A pesca indiscriminada nos períodos de reprodução. 
O trabalho com os produtos das baleias, considerado menos arriscado que a pesca, era feito pelos escravos, com população variando entre 20 e 80 nas armações. Também estavam presentes nas armações baleeiras o administrador da armação e os feitores - assalariados pagos ou pelo contratante ou diretamente pela Coroa quando a armação não estava arrendada.

A prática de pescar baleias com arpões foi inaugurada no Brasil no início do século XVII, por influência direta de pescadores bascos instalados na Bahia. Desde o início, precisamente em 1614, a Coroa estabeleceu o monopólio sobre esta atividade, garantindo o controle dos impostos, da qualificação social dos seus administradores e do destino do produto da pesca. A indústria baleeira foi uma das atividades que Portugal permitiu no Brasil Colonial. Durante o século XVII, a Bahia foi a principal produtora de óleo, mas, com o aval da Coroa para implementação de novas armações sempre descendo pela costa brasileira, já no século XVIII as principais armações eram as do sul - Rio de Janeiro, São Paulo e Santa Catarina.

A pesca no litoral de Santa Catarina, século XVII, teve seu primeiro incentivo em 1747, com o conselho ultramarino de Lisboa em Portugal determinando a aplicação de editais nas ilhas do arquipélago de Açores e, a quem quisesse vir se estabelecer no Brasil, o governo facultava o transporte à custa da fazenda real aos açorianos e madeirenses, saídos da terra natal, poderiam então transformar-se em pequenos produtores, em áreas cedidas no espaço catarinense. De início instalou-se povoados nos núcleos de São Miguel, Ganchos, Bombas, Zimbros e Tijuquinhas, além da enseada de Brito, São José, Palhoça, Paulo Lopes, Garopaba e Vila Nova, e mais para o Sul. Nestas regiões predominava, na época, a pesca de baleia, captura e manufatura, tornando-se o maior posto de pesca e manufatura do Brasil Colônia.

Pode-se dizer que a pesca da baleia foi importante atividade econômica exercida na América portuguesa no século XVIII, sendo fonte de exploração de holandeses, norte-americanos e ingleses, e depois noruegueses e japoneses. Já no início do século XIX com a reestruturação do monopólio de pesca baleeira exercida pela Coroa, com novos arrendamentos, ocorreram outros empreendimentos, feitas pelo Marquês de Pombal, grande aliado da burguesia mercantil do Reino. Tais empreendimentos permitiram, por um lado, a organização da pesca ou o início de formação das colônias e armações para melhor serem administradas e, por outro, o começo da exploração indiscriminada que termina por volta de 1970 em Santa Catarina.

Até o período compreendido entre $1847 / 51$ a pesca da baleia era uma atividade de grande importância para a população. Porém com a decadência desta atividade a população litorânea diminuiu significativamente. Por volta de 1816 as armações baleeiras começaram a desaparecer com algumas postas a venda pela Coroa portuguesa. Em algumas armações, 
com a inadimplência dos pagamentos dos administradores locais e dos trabalhadores escravos, havia fugas, e até mesmo utilização da estrutura da armação por pescadores estrangeiros, principalmente norte-americanos. Muitos indivíduos, devido a tais condições, estabeleceram-se em outras comunidades vizinhas, em núcleos de produção de gênero agrícola. A partir daí surgiram às grandes plantações e intensificaram as manufaturas de mandioca e de cana de açúcar, além de plantações de café, banana, milho, algodão e feijão em pequena escala para subsistência. Em Itajaí, por exemplo, município considerado o mais industrializado de Santa Catarina neste setor, o de pesca, neste período poucos se aventuravam em mar e uma das atividades mais importantes era o comercio de madeiras, transportadas ao Rio de Janeiro e Santos. Durante muitos anos a economia de Itajaí baseou-se na madeira, fato que desenvolveu também a função portuária. Porém no sul como Barra Velha, Barra do Sul e Enseada a atividade de pesca de baleia foi exercida até finais do século XIX, junto à pequena atividade de agricultura de subsistência.

Em busca de um ganho extra, além da agricultura, pois as condições de miserabilidade exigiam povoados do litoral começaram a exercer a pesca de subsistência. A princípio a pesca de subsistência lhes fornecia uma renda para suprir outras necessidades, das quais dependia da necessidade de primeira ordem de cada família. Aos poucos, este ganho extra começou a ser investido na pequena produção, como as salgas, redes, barcos e outros instrumentos de auxilio a pesca. Sobretudo no período compreendido entre 1873-1896 surgiram no litoral de Santa Catarina esta forma de conservar tais produtos oriundos do mar, as salgas. Pode-se se dizer que devido a esta nova forma de conservação do pescado houve uma reorganização econômica nas localidades cuja atividade pesqueira vinha sendo praticada. Tal conservação permitiu a separação da pesca marítima em dois setores: o primeiro de extração dos recursos naturais e conservação para o comercio, e o segundo que era produzir os meios de produção para tal atividade. Neste caso, a divisão do pescado era efetuada entre os demais trabalhadores e o produto destinado ao consumo ou vendida à parte excedente.

Os imigrantes açorianos que desde 1740 vieram povoar o litoral de Santa Catarina eram agricultores que praticavam a pequena pesca como atividade sazonal, cujo produto uma vez vendido the fornecia o dinheiro necessário para comprar as mercadorias que não produziam. Efetivamente a pesca da tainha e da anchova era realizada como pequenas redes de praia e canoas a remo, dentro dos moldes das "Campanhas", marcadas por certo igualitarismo. Esta pesca era exercida pelos membros da comunidade dos pescadores sitiantes do litoral catarinense. Conforme a descrição de (LAGO, 1968), constata-se que tradicionalmente a campanha, uma sociedade agrário-pesqueira, era uma unidade de produção composta por membros de uma família.

${ }_{3}^{3}$ Grupo de trabalhadores do mar que procuravam o sustento na atividade da pesca marítima. 
A desorganização desta sociedade agrário-pesqueira, com o aparecimento de um grande número de ex-agricultores-pescadores, que passaram a viver exclusivamente da pesca só se dá a partir da década de 1914. A crise agrária local teve como principais causas o tratamento do solo por usar técnicas absoletas, e de pragas existentes em mudas, ocorrendo nas décadas de 1940/50, uma evasão da população em determinados povoados açorianos para exercer, exclusivamente, seu trabalho na atividade pesqueira. Por sua vez, a renda baixa auferida na agricultura forçava seus participantes a se entregarem cada vez mais a atividade pesqueira. A competição com mercadorias de outras áreas agrícolas do interior também foi um fator que motivou a desorganização da pequena agricultura, deixando a pesca como alternativa de trabalho as famílias litorâneas.

Essa passagem maciça da agricultura para a pesca era prenúncio de situações difíceis, onde a formação de inúmeras campanhas em praias onde a produção começava a escassear. Assim, (LAGO. 1968) explicitam este fato ocorrido por volta da segunda metade do Século XX:

\begin{abstract}
Nas áreas de arrastão de praia, a luta pelos melhores pontos de praia já eram comum e absorviam proporções de graves conflitos, como na praia dos Ingleses. Este fato esbarrava, é verdade, nas determinações legais que reagem à propriedade privada das águas. Entretanto, a chegada das tainhas assinala a identificação de conflitos entre campanhas de uma mesma comunidade.
\end{abstract}

O surgimento de grandes arrastões de praia significou também o aparecimento de proprietários de redes. Estes eram representados pelos patrões de pesca e mestres de redes que organizavam o lance e a puxada de redes de praia. Ainda, estes patrões eram às vezes assalariados pelo próprio proprietário dos meios de produção que não participavam da pesca em mar. Tal arrastão ou campanhas só não se tornou industrial capitalista de pesca por ter dizimado precocemente os recursos pesqueiros próximos às praias, daí a diferença primordial na atividade pesqueira das outras de divisão social do trabalho. Por esta questão se tornou inviável tal acumulação antes da segunda metade do século XX em Santa Catarina.

A introdução de traineiras, já nas primeiras décadas do século XX, representou o primeiro passo para a concentração dos meios de produção e da força de trabalho na pesca. Não se tratava, porém, no entanto, de um empreendimento-capitalista empresarial, pois o dono das traineiras ou eram mestres ou o patrão de pesca, que participava diretamente do processo de trabalho, junto com os embarcados, muitas vezes parentes ou conhecidos. 
À medida que estes donos de traineiras conseguem acumular primitivamente capitais, comprando outras traineiras e "barcos linheiros" (Pesca realizada com linhas de mão lançadas a partir de pequenos botes, que por sua vez, eram levados em alto-mar por uma embarcação maior), começam dialeticamente se afastando do processo de trabalho, passando a desempenhar o papel de administrador ou comerciante, chamados de armadores.

Alguns pescadores, que possuíam certo conhecimento sobre a pesca, pescadores artesanais, e alguns meio para exercer a atividade, resistiram às empresas de pesca, outros migraram para regiões sul do estado ou procuram estabelecer-se em outras indústrias, exercendo outras atividades. Está resistência da pesca artesanal se tornava mais forte à medida que o número de pescadores aumentava ano a ano, promovendo assim grandes perseguições do poder publico as colônias para a realização de seus propósitos. Ainda, entre os anos de 1965-66, houve uma estagnação do número de pescadores artesanais, este fato ocorreu quando houve maior perseguição ao pescador artesanal, diante de um aumento de quase $300 \%$ do número de pescadores artesanais nos anos de 1963/64, houve uma expropriação das condições objetivas de seu trabalho, passando estes a submeterem aos interesses mercantis.

A significativa redução da matéria prima a ser capturada por parte dos pescadores artesanais, pois as tecnologias adotadas pelas empresas de pesca estavam muito avançadas e aptas para tal atividade em mar. A indisponibilidade de pescado representa um dos principais condicionantes do agravamento de produção e reprodução socioeconômica e cultural das comunidades de pescadores artesanais sediadas na zona costeira catarinense. Fato este que está associado ao crescimento econômico na atividade pesqueira a partir da segunda metade do século XX.

\section{Dos conflitos à crise no litoral catarinense}

A idéia de desenvolvimento econômico que é introduzida no litoral catarinense durante o século XX evidencia a desvalorização da pesca artesanal. O discurso obtido nas mensagens presidenciais e leis, decretos, só fazem sentido quando há uma desvalorização de uma forma de produção que não serve para o mercado, onde capitais estabelecem relações entre coisas, ou ainda, uma produção em larga escala e padronizada daria ao Brasil um status de país industrializado na busca de um modelo econômico respeitado através de uma imposição cultural e introdução das relações capitalistas de produção.

Assim, "os conflitos sócio-ambientais podem ser entendidos como disputas entre grupos sociais derivadas dos distintos tipos de relações por eles mantidas com seu meio natural". Há três dimensões básicas a serem consideradas, neste sentido, no entendimento e na análise destes conflitos: o mundo biofísico e os ciclos naturais, o mundo humano e suas estruturas sociais, 
e o relacionamento dinâmico, interdependente entre estes dois mundos. Ocorrem conflitos pelo controle dos recursos naturais, conflitos derivados dos impactos ambientais e sociais decorrentes de determinados usos, e também aqueles ligados aos usos e apropriações dos conhecimentos ambientais, todos pertencentes à introdução das relações entre coisas no "mundo encantado das mercadorias".

Então, ao final da década de 1960 a pesca e as comunidades de pescadores começaram a ser percebidas dentro de um contexto mais amplo da sociedade nacional, da penetração das relações capitalistas no setor, dos conflitos entre pesca realizada nos moldes da pequena produção mercantil e a capitalista. Podemos perceber que os municípios que possuíam conflitos de produção no litoral catarinense se limitavam de Itajaí a Florianópolis pois industrializaram tal atividade rapidamente com os incentivos da SUDEPE a partir de 1967. Porém os municípios mais ao sul possuiam moderado conflito em consideração ao número de estabelecimentos.

Ainda, nas décadas de 1960/70, já evidenciavam conflitos tradicionais desta atividade, entre colônias e pescadores residia no fato de esta atuar muito pouco pela categoria Desde a criação das colônias, em 1922, e a obrigação das devidas matriculas dos pescadores já se estabelecia conflitos de ordens sociais. Com o crescimento industrial da pesca e a reorganização espacial, trouxeram como ponto de vista negativo a expropriação das pequenas manufaturas, no sentido legal das atividades, não no seu desaparecimento como produção clandestina. A perseguição foi um fato e isto criou sérios problemas para as pequenas manufaturas, mas não afastou os pequenos produtores artesanais das atividades no mar. Este fato também causou uma mudança interna da população. Os que venderam suas terras próximas às áreas litorâneas buscaram uma mudança de vida e se afastaram da praia perdendo seus meios de produção e acabaram por vender sua força de trabalho para a pesca industrial.

Durante o século XX o estado promoveu políticas para este setor de duas formas distintas: na primeira, sobretudo a partir de 1930 regulamentando o setor com objetivo de incrementar a produção que predominantemente era exercida pela pesca artesanal, e na segunda, a partir de 1955, incentivou financeiramente a construção de uma indústria capitalista pesqueira para modernizar o setor. Através dos incentivos fiscais e financeiros oferecidos pelo estado, capitais industriais migraram para a atividade pesqueira catarinense. Empresas como Volkswagen do Brasil e Atlantic S/A já detinham mais de 50\% do capital investido por intermédio dos incentivos fiscais. Deduções tributárias, isenção de taxas federais e impostos para importações de máquinas, equipamentos e todo o tipo de apetrecho como: radares e sonares evidenciaram uma transformação na atividade pesqueira no litoral catarinense de grandes proporções, desmotivando a pesca artesanal. 


\section{Hümanas}

A moderna indústria em mar e terra trazia esperança à população que vivia a miséria, condições propiciadas pelo estado e os industriais. O estado catarinense criou centros de treinamento para pescadores, escolas, crédito, planos, projetos, em convênios com a SUDEPE e na maioria dos acordos apresentava mais possibilidades de investimentos de infra-estrutura em terra, porém em nenhum momento empreendeu um estudo sobre a produção e preservação de algumas espécies importantes para o ecossistema marinho das espécies mais visadas logo quando surgiu o debate ambiental na década de 1970 (Estocolmo). A pesca artesanal, o que restou, por sua vez, sofreu grande concorrência dos barcos que adentravam nas baias, presenciando seus instrumentos de trabalho sendo arrastados, sem direito a reivindicação. Assim, deste modo, o capitalismo, na proporção que deixa as empresas organizarem-se da melhor forma que lhe convier.

A crise na atividade pesqueira que se instalou, sobretudo a partir de 1980, não foi simplesmente financeira como costuma se dizer em meio ao empresariado. Além dos problemas econômicos brasileiros, havia uma pesca predatória visível ao longo do litoral catarinense. O decréscimo da produção foi inevitável como podemos ver na tabela 1 , e as condições para exercer esta atividade no litoral já não davam conta de produzir a vida material dos pescadores artesanais. Com a grande concentração destas embarcações industriais, determinadas espécies marinhas com maior valor comercial para exportação, foram depredadas, apresentando este novo cenário. Conforme o Jornal Olho $\mathrm{Nu}$ em junho de 2003 nos demonstra:

Desde o dia 27 de janeiro até a segunda semana de fevereiro, ocorreu pesca predatória na área do Parque e Praia da Galheta. Em sua maioria, eram grandes barcos pesqueiros fazendo cerco e arrastão junto à praia e costões do Parque. Muito lixo de cozinha e esgoto dos barcos foi jogado no mar e chegou até a Praia, num evidente complô contra a preservação daquele local. Até cavalos marinhos encontramos mortos e machucados pelas redes de arrasto [...]

A saber, as espécies de camarões eram as primeiras de uma cadeia alimentar de espécies importantes e foram fortemente visadas e depredadas. Ainda segundo a SUDEPE, (1985) afirmou que:

Particularmente, desde 1980, assistimos a decadência acelerada de seus serviços, junto as Comunidades Pesqueiras: Primeiro, pela ineficácia de suas atividades junto aos problemas vitais pela classe principalmente no que se refere à sua organização político - social e econômica. 
Apesar do dinheiro fácil fornecido com intuito de criar um setor pesqueiro industrializado, o empresariado pesqueiro introduziu a idéia de crise de custos financeiros. Com o choque do petróleo além dos fatos levantados e que teve conseqüências na desestruturação da pesca, as várias crises do aumento do petróleo também ajudaram a criar problemas para a produção pesqueira em Santa Catarina.

Tabela 1

Produção pesqueira Catarinense entre 1960 a $2000 \mathrm{em}$ toneladas.

\begin{tabular}{l|c|c|c|c|c|c|c|c|c}
\hline Ano/Estado & $\mathbf{1 9 6 0}$ & $\mathbf{1 9 6 5}$ & $\mathbf{1 9 7 0}$ & $\mathbf{1 9 7 5}$ & $\mathbf{1 9 8 0}$ & $\mathbf{1 9 8 5}$ & $\mathbf{1 9 9 0}$ & $\mathbf{1 9 9 5}$ & $\mathbf{2 0 0 0}$ \\
\hline $\begin{array}{l}\text { Santa } \\
\text { Catarina }\end{array}$ & 54.845 & 70.257 & 103.477 & 157.812 & 136.712 & 125.730 & 64.741 & 75.182 & 71.042 \\
\hline
\end{tabular}

Fonte: Anuário Estatístico do Brasil

Durante a década de 1960/70 a produção pesqueira pelo litoral catarinense, de Itapoá á Passo de torres manteve-se em gradativo aumento. Este incremento na produção de ano a ano fui sem dúvida nenhuma decorrente das políticas do estado junto ao empresariado de muitos setores de produção. Empresas se viam atraídas pelos incentivos a exploração do pescado no litoral catarinense, assim como a oportunidade de obter taxas de lucro acima do que normalmente se praticava. Porém o uso indevido tanto dos recursos naturais, que possui suas devidas restrições de produção, como também dos recursos financeiros do estado decretou a falência de um setor em seu berço de industrialização.

As transformações econômicas do setor pesqueiro catarinense e dos outros setores influenciaram e afetaram a pequena pesca artesanal. Isso se traduz na saída de pescadores artesanais para a pesca industrial em outros portos como o de Itajaí/SC, Rio Grande/RS, Santos/SP e Rio de Janeiro/RJ. Desse modo, os problemas advindos da falência das indústrias locais deixaram "órfãos", não somente os que dependiam da grande produção industrial onde vendiam seu trabalho, mas também o pescador artesanal que ao retornar às suas atividades, não encontrava muito a capturar. Assim, o estado de Santa Catarina passou por uma reorganização espacial traduzida na busca de alternativas como forma de sobrevivência. Os problemas econômicos e sociais provocados pela falência da indústria pesqueira afetaram muito mais a questão de sobrevivência do pescador artesanal na busca de sua existência do que a ascensão dessas mesmas empresas industriais. Alguns pequenos pescadores artesanais que conseguiram acumular alguma poupança financeira passaram a investir em comércio como padarias, mini-mercados, lojas de conveniência, restaurantes e bares, entre outros. Enquanto a família cuidava do comércio, porém em sua maioria sofreu grande impacto na sua vida social. 
Além da alternativa de alterar o período de defeso, muitos pescadores artesãos defendem a idéia de criar novas políticas de regulamentação para o setor. Por outro lado o empresariado reinvidica maiores investimentos estatais no setor, além da "migração" de pescadores artesanais para a atividade industrial. Ainda, pescadores artesanais pedem a inserção das colônias e sindicatos da pesca artesanal e dos trabalhadores do mar nas lutas pelos direitos da classe, pois desde 1922, as colônias têm exercido papel central na submissão dos pescadores catarinenses diante do estado, sindicatos patronais e industriais.

É importante salientar que com a extinção da SUDEPE e a Criação do IBAMA (Instituto Brasileiro de Meio Ambiente e dos Recursos Naturais Renováveis) a partir da década de 1990 deu outro caráter à fiscalização exercida no litoral, tanto à pesca artesanal quanto industrial, porém não foi capaz de solucionar problemas sócio-ambientais de forma dinâmica e definitiva, pois o problema ambiental é sem dúvida um problema do sistema produtor de mercadorias. Aliás, a década de 1990 para a economia brasileira em geral não trouxe novas esperanças, pelo contrario, esta década iniciou demonstrando a grande fragilidade nacional diante das novas políticas e planos para cada setor. Se o setor pesqueiro entra em crise a partir de 1980, em 1990 aprofundam ainda mais as contradições e conflitos.

Só a partir de 2003 é que retoma novamente o discurso de desenvolvimento pesqueiro, seguindo a mesma lógica mercantil. Com a experiência tanto ambiental, como social e econômica da atividade, o SEAP discute novas políticas conservadoras para atuarem junto aos pescadores artesanais, de forma assistencial, aos trabalhadores do mar políticas de assalariamento com sindicatos frágeis, e ao empresariado catarinense acordos internacionais. Nos moldes atuais a pesca se diferencia em grande parte daquela estabelecida nas décadas pós 1929, Se por um o estado efetivamente exerceu influencia e teve um grande ideal desenvolvimentista em suas políticas, o estado de hoje apresenta suas características assistencialistas como remedi ação dos conflitos gerados por ele mesmo.

\section{Considerações finais}

As políticas do estado, a vontade empresarial, e o trabalho exercido por "pescadores" em geral, transformaram o litoral catarinense. A pesca foi sem dúvida uma das primeiras atividades de indivíduos que se estabeleceram ao longo do litoral a partir do século XVII. Fruto de iniciativas do estado nacional para assentar açorianos e madeirenses e não perder território aos espanhóis e, mais tarde, impedindo estrangeiros de exercer esta atividade no litoral nacional, pois grandes indústrias flutuantes de pesca internacionais praticavam na costa brasileira tal atividade, além de criar plano de metas, o estado se fez interventor durante quase dois séculos e meio no Brasil. 
Ao alcançar patamares de produção nunca antes visto a pesca representou para algumas famílias litorâneas o novo, a modernidade. Se por um lado a pesca em Passo de Torres a Imaruí foi basicamente artesanal após 1960 e não apresentou grandes mudanças no cotidiano das comunidades, do norte até Laguna representou junto aos portos as mudanças da modernidade e também a distorção dos valores de ser um pescador.

As questões conflituosas acerca da pesca se referem exclusivamente a esta inserção do novo e ao uso indevido e indiscriminado da natureza e refletido nas comunidades ribeirinhas e municípios pesqueiros onde a pesca artesanal foi ou ainda é muito importante. O desrespeito ao período de defeso ou a pratica da sobrepesca, assim como, da depredação dos meios de produção dos pescadores artesanais pelas empresas industrial-capitalistas, além das questões de lançar aos mares resíduos industriais não são mero acaso no cotidiano da população no litoral. Não se trata aqui de somente fazer indagações ambientalistas sobre questões morais e éticas sobre a natureza, porém, compreender estas questões numa determinada sociedade, no capitalismo em geral.

\section{Referências bibliográficas}

ANUÁRIO ESTATÍSTICO. Matérias-primas e produtos de origem animal. Brasília: Secretaria Nacional de Defesa Agropecuária, SIPA, 1980-86.

ANUÁRIO ESTATÍSTICO DO BRASIL. Rio de Janeiro: FIBGE, 1973-93.

CUNHA, I. Conflito ambiental em águas costeiras. Ambiente \& Sociedade, p. 83-98, 2003.

DECRETO 1.951 (1 de Agosto de 1857). Autoriza a incorporação e aprova os Estatutos da Companhia - Nereida - que tem por fim exercer a indústria da pesca e salga de peixe entre o Rio de Janeiro e os Abrolhos). Brasília: Senado Federal.

DECRETO 9379 (14 de Fevereiro de 1885). Atendendo ao que requereu Antonio Candido de Siqueira, Hei por bem Conceder-lhe, ou á companhia que organizar, para a pesca, salga e secca de peixe. Brasília: Senado Federal.

DECRETO-LEI 1.240 (3 de Maio de 1939). Desapropria, por utilidade pública, os terrenos pertencentes a João Pedro da Rosa. Brasília: Senado Federal.

DECRETO-LEI 221 (28 de Fevereiro de 1967). Dispõe sobre proteção e estímulo a pesca. Brasília: Senado Federal.

DIEGUES, A.C.S. Pescadores, camponeses e trabalhadores do mar. São Paulo: Editora Ática, 1983. 
GOULARTI, A.F. Formação econômica de Santa Catarina. Florianópolis: Editora Cidade Futura, 2002.

JORNAL OLHO NU. Pesca Predatória na área da praia. 34:.1 (www.jornalolhonu.jn.net. Acesso em 5 de Fevereiro/2009).

LAGO, P.F. Comunidades pesqueiras catarinenses. Rio de Janeiro: Editora SAI/MA, 1968.

MARX, K. O Capital. Rio de Janeiro: Civilização Brasileira, 1968.

PIAZZA, W.F. Santa Catarina: sua história. Florianópolis: EdUFSC e Editora Lunardelli, 1991.

SILVA, J.G. O novo rural brasileiro. São Paulo: IE/UNICAMP, 1999.

SUDEPE/DPD. Relatório da IV Reunião do Grupo Permanente de Estudos sobre Camarão (Santos/SP, em Setembro de 1983). Brasília: Instituto de Pesquisa e Desenvolvimento Pesqueiro/ Série Documentos Técnicos, 33: 129-173, 1985.

SUDEPE/DPD. Plano Nacional do Desenvolvimento da Pesca -1975/1979. Brasília: SUDEPE, 1975.

SUDEPE/DPD. IV Plano Nacional de Desenvolvimento da Pesca - 19801985. Brasília, SUDEPE, 1979a.

SUDEPE/DPD. Nova estratégia operacional da SUDEPE: um enfoque sistêmico do setor pesqueiro. Brasília: SUDEPE, 1979b. 